DOI: 10.20472/IAC.2018.040.041

JOAO LOPES

UECE - University of Lisbon, Portugal

\title{
THE ECONOMIC CONSEQUENCES OF MIGRATION: AN INPUT-OUTPUT APPROACH
}

\begin{abstract}
:
The main purpose of this paper is to contribute for a better understanding of the economic consequences of migration. In a first step, the different consumption patterns of nationals and foreigners are measured, using data from a Family Income and Expenditure Survey in Portugal (Inquérito às Despesas das Famílias, 2010/2011). Households are grouped according to the proportion of foreigners and the consumption structures of these groups are determined and compared. This information is useful in assessing the differences in living conditions across national and migrant families. In a second step, the sectoral and macroeconomic impacts (in Gross Output, Value Added, GDP and Imports) of these different consumption structures are simulated, using an Input-Output approach. These results allow us to project the demand led effects of a growing in-migration flow to Portugal, (both of workers and retirees) expected for the coming years. In a third (future) step of this research project, other consequences of migration will also be studied, namely, supply side effects (labor force, wages and profits, productivity), government budget and social security income and expenditure effects, demographic trend effects, etc.
\end{abstract}

\section{Keywords:}

Migration; Input-Output Analysis; Consumption Patterns; Macroeconomic and Sectoral Effects; Portugal

JEL Classification: D57, E27, F22 